\title{
DEXMEDETOMIDINE IN EMERGENCY HAND SURGERY AS AN ADJUVANT TO ROPIVACAINE-INDUCED SUPRACLAVICULAR BRACHIAL PLEXUS BLOCK: A PROSPECTIVE, DOUBLE-BLINDED AND RANDOMIZED CONTROLLED STUDY
}

\author{
Sudipta Kumar Mandal ${ }^{1}$, Koyel Das ${ }^{2}$, Anjan Das 3 , Subhadeep Basak ${ }^{4}$, Subrata Bisai ${ }^{5}$, Saptarshi Bhattacharya ${ }^{6}$ \\ ${ }^{1}$ Assistant Professor, Department of Anaesthesiology, College of Medicine \& Sagore Dutta Hospital, Kolkata. \\ 22nd Year Junior Resident, Department of Pathology, R. G. Kar Medical College \& Hospital, Kolkata. \\ ${ }^{3}$ Assistant Professor, Department of Anaesthesiology, College of Medicine \& Sagore Dutta Hospital, Kolkata. \\ ${ }^{4}$ Assistant Professor, Department of Obstetrics \& Gynaecology, College of Medicine \& Sagore Dutta Hospital, Kolkata. \\ ${ }^{5}$ RMO cum Clinical Tutor, Department of Anaesthesiology, College of Medicine \& Sagore Dutta Hospital, Kolkata. \\ ${ }^{6}$ RMO cum Clinical Tutor, Department of Anaesthesiology, College of Medicine \& Sagore Dutta Hospital, Kolkata.
}

\section{ABSTRACT}

\section{BACKGROUND}

Accidental industrial hand injury very often requires early intervention. Assuming as full stomach condition, regional anaesthesia is preferred to avoid the risk of aspiration in general anaesthesia. Different additives have been used to prolong the duration of brachial plexus block. We evaluated the effect of adding dexmedetomidine to ropivacaine for supraclavicular brachial plexus blockade. The primary endpoints were the onset and duration of sensory and motor block and duration of analgesia.

\section{MATERIALS AND METHODS}

Seventy six patients aged 20-50 years with ASA grade I, II who were presented with industrial hand injury and required emergency operative interventions were randomly allocated into two groups. Group-RD $(\mathrm{n}=38)$ received ropivacaine $(30 \mathrm{ml} 0.5 \%)$ with dexmedetomidine $1 \mathrm{ml}(100 \mu \mathrm{g})$ and patients in group- $\mathrm{RP}(\mathrm{n}=38)$ received ropivacaine $(30 \mathrm{ml} 0.5 \%)$ with $0.9 \%$ normal saline $1 \mathrm{ml}$ solution as placebo. Sensory and motor block onset times and durations, time to first analgesic use, total analgesic need, postoperative VAS, hemodynamics and side effects were recorded for each patient.

\section{RESULTS}

Though having comparable demographic profile, the onset of motor and sensory block was significantly fastened by dexmedetomidine $(\mathrm{p}<0.05)$. Sensory and motor block duration and time to first analgesic use were significantly prolonged and the total need for rescue analgesics was lower in group RD $(\mathrm{P}<0.05)$ than group RD. Postoperative VAS value at 12 hours were significantly lower in group $\mathrm{RD}(\mathrm{P}<0.05)$. Side effects and hemodynamics were quite comparable among two groups.

\section{CONCLUSION}

It can be concluded that adding dexmedetomidine to brachial plexus block increases the sensory and motor block duration and time to first analgesic use and decreases block onset time and total analgesic use with no side effects.

\section{KEYWORDS \\ Industrial Hand Injury, Dexmedetomidine, Ropivacaine, Supraclavicular Brachial Plexus Block.}

HOW TO CITE THIS ARTICLE: Sudipta Kumar Mandal, Koyel Das, Anjan Das, Subhadeep Basak, Subrata Bisai, Saptarshi Bhattacharya. "Dexmedetomidine in Emergency Hand Surgery as an Adjuvant to Ropivacaine-Induced Supraclavicular Brachial Plexus Block: A Prospective, Double-Blinded and Randomized Controlled Study." Journal of Evolution of Medical and Dental Sciences 2015; Vol. 4, Issue 98, December 07; Page: 16320-16325, D0I: 10.14260/jemds/2015/2409

\section{INTRODUCTION}

Accidental injuries to the upper limb can cause major financial loss due to time away from work and medical expenses. It may also result in permanent deformities and dysfunction of the hand, which can be avoided or reduced with proper earliest intervention. It is found that incidence of upper limb injuries are high among the people engaged in different industry specially agriculture, forestry and fishing, manufacturing, construction, whole sale and retail trade, mining and even health services.[1] Since our hospital is surrounded by a large number of manufacturing industry, construction industry, we get a large number of people with such injury in our Emergency Department. Most of them come from their place of work with full stomach or without any definitive history of food intake. This brings risk of aspiration under general

Financial or Other, Competing Interest: None.

Submission 18-11-2015, Peer Review 19-11-2015,

Acceptance 01-12-2015, Published 05-12-2015.

Corresponding Author:

Dr. Anjan Das,

174, Gorakshabashi Road, Royal Plaza Apartment,

$4^{\text {th }}$ Floor, Flat No-1, Nagerbazar,

Dumdum.

E-mail:anjan2k8@yahoo.com

DOI:10.14260/jemds/2015/2409 anaesthesia. Regional anaesthesia in the form of brachial plexus block is very useful in such situation.

Ropivacaine, a local anaesthetic drug has got low cardiovascular and neurotoxicity. It is frequently used for regional nerve block. Local anesthetics alone for supraclavicular brachial plexus block provide good operative conditions, but have a shorter duration of postoperative analgesia. But complex reconstructive procedures may often require longer duration. To address this need, different investigators have always been trying to improve duration of motor and sensory block as well as analgesic effect of local anaesthetics using an adjuvant like opioids.[2] clonidine. ${ }^{[3]}$ neostigmine, dexamethasone.[4] midazolam. ${ }^{[5]}$ magnesium. ${ }^{[6]}$ etc. Dexmedetomidine is highly selective (Eight time more selective than clonidine).[7] specific and potent $\alpha_{2}$-adrenergic agonist having analgesic, sedative, antihypertensive and anaesthetic sparing effects when used in systemic route.[8]

Adding dexmedetomidine to local anaesthetics during peripheral nerve blockade.[9] and regional anesthesia.[10] procedures may also prove efficacious for the surgical patients. In human study, dexmedetomidine has also shown to prolong the duration of block and post-operative analgesia when added to local anaesthetic in various regional blocks.[11,12] In our placebo control double blind study, we combined dexmedetomidine with ropivacaine and compared 
its effects on duration of analgesia as well as motor and sensory block (Onset as well as duration) characteristics in patients with industrial hand injuries who required operative interventions under brachial plexus block.

\section{MATERIALS AND METHODS}

After getting permission from institutional ethical committee and written informed consent from every patient, this double blind placebo controlled parallel group study was conducted in a Tertiary Care Center. Seventy six patients aged between 20 to 50 years with ASA physical status I and II who were presented with industrial hand injury and required operative interventions in the Emergency Department of our institute were randomly allocated into two groups, patients in group$\mathrm{RD} \quad(\mathrm{n}=38)$ received ropivacaine $(30 \mathrm{ml} 0.5 \%)$ with dexmedetomidine $(100 \mu \mathrm{g}=1 \mathrm{ml})$ and patients in group-RP $(\mathrm{n}=38)$ received ropivacaine $(30 \mathrm{ml} 0.5 \%)$ with $0.9 \% \mathrm{NaCl}$ $(1 \mathrm{ml})$ solution as placebo.

Patients having cardio-pulmonary, neurological, hepatic, renal diseases, coagulopathy, diabetes, infection at the site of injection were excluded from the study. Those were having history of allergy to amide local anaesthetics, pregnant and lactating mothers were also excluded from study. Those patients associated with other injury like head and neck, chest or abdominal blunt or open injury were also excluded.

After thorough clinical examination and airway assessment, all the patients were explained about the procedure and $10 \mathrm{~cm}$ Visual Analogue Scale (VAS) (0 no pain and 10 worst pain imaginable). No patient was pre-medicated until they arrived in the operating room, where midazolam was given intravenously to a maximum of $3.0 \mathrm{mg}$ to relieve anxiety before administration of the block. In the operative room standard intraoperative monitors like ECG, pulse oximeter, non-invasive blood pressure was attached and baseline parameters were recorded. Vital parameters were recorded after 2, 5, 10, 15, 20, 25, 30, 45 and $60 \mathrm{~min}$ after the block; and then every $30 \mathrm{~min}$ for an additional $2 \mathrm{hr}$.

After proper explanation of technique and positioning, supraclavicular groove was identified and a mark was made approximately 1.5 to $2.0 \mathrm{~cm}$ posterior to the mid-clavicle point. The stimulation frequency was set at $1 \mathrm{~Hz}$ and the intensity of the stimulating current was initially set to deliver $2 \mathrm{~mA}$ and was then gradually decreased. The 22 -gauge $5 \mathrm{~cm}$ insulated, Stimuplex® A needle was used. The position of the needle was considered to be acceptable when an output current $<0.5 \mathrm{~mA}$ still elicited a slight distal motor response in forearm and hand. On negative aspiration for blood, a total volume of $31 \mathrm{ml}$ solution was injected slowly as per allotment of the group and drug. Needle position relocated if there is pain on injection. The anaesthesiologist performing supraclavicular block was unaware of the constituent of the drug and allotment of the group and similarly resident doctors keeping records of different parameters were also unaware of group allotment.

Immediately after block placement, patients were evaluated every $1 \mathrm{~min}$, by a resident doctor of Anaesthesiology Department unaware of the injected solution to determine loss of pinprick sensation and loss of flexion of forearm as an evidence of a successful sensory and motor blockade respectively. Failure to produce adequate motor block after 30 min was considered as block failure. These patients were excluded from statistical analysis. Time to onset of motor and sensory block was notified from end of local anaesthetic injection. After evidence of a successful sensory and motor block, the patient was taken for surgery. Tourniquet to the arm was applied and time noticed. All episodes of local anesthetic toxicity or hemodynamic change requiring anaesthesiologist intervention (Increased IV fluids or inotropes) were recorded as adverse events. Tourniquet time, operative time and duration of anaesthesia were recorded. At the conclusion of surgery, all patients were transferred to the PACU.

For the next $5 \mathrm{~h}$, sensory and motor function were evaluated every $15 \mathrm{~min}$, for the subsequent $7 \mathrm{~h}$ every $30 \mathrm{~min}$, and then every $60 \mathrm{~min}$ until recovery was complete. Sensory function was assessed as no loss of sensation to pinprick was scored as 0; analgesia (Patient feels touch, but not pinprick) was scored as 1; and anaesthesia (Patient does not even feel touch) was scored as 2 . Motor function was graded such that no weakness was scored as 0 , paresis was scored as 1 , and paralysis was scored as 2 . The duration of sensory block was defined as the time interval between the injection of local anaesthetic solution and return of sensory function clinically (Sensory score 0 ).

The duration of motor block was defined as the time interval between the injection and complete recovery of motor functions (Motor score 0). Duration of analgesia was defined as time interval between injection and first request for analgesia or VAS score $\geq 3 \mathrm{~cm}$. Injection diclofenac sodium (Rescue analgesic) $75 \mathrm{mg}$ was given intramuscularly when VAS $\geq 3 \mathrm{~cm}$. Total amount of injection diclofenac given to each patient during first 24 hours of postoperative period was recorded.

\section{STATISTICAL ANALYSIS}

Sample size was estimated using first rescue analgesic requirement among two groups as the main primary variable. The average duration in each group was $510 \mathrm{~min}$ and to detect a difference of $10 \%$ (i.e. $51 \mathrm{~min}$ ), at the $\mathrm{P}<0.05$ level with a probability of detecting a difference of 80 percent (1-beta=0.80). On the basis of previous study assuming that within group SD was 80 min and we needed to study at least 35 patients per group to be able to reject the null hypothesis, which may be increased to 40 patients per group for possible dropouts. Raw data were entered into an MS Excel spreadsheet and analysed using standard statistical software SPSS $®$ statistical package version 18.0 (SPSS Inc., Chicago, IL, USA). Categorical variables were analysed using the Pearson's Chi square test. Normally distributed continuous variables were analysed using the independent sample t test and $P$ value $<0.05$ was considered statistically significant.

\section{RESULTS AND ANALYSIS}

We recruited 40 subjects per group, more than the calculated sample size, to exclude probable dropouts and failed blocks. There was no incidence of drop out. However, excluding subjects those have failed blocks, 38 patients in the dexmedetomidine group (RD) and 38 in the normal saline group (RP) were eligible for analysis. The age, body weight, sex distribution, height, ASA status and duration of surgery, tourniquet time and anaesthesia time in the two groups were found to be comparable [Table - 1]. Indications for different upper limb surgeries were also similar and have no clinical significance [Table - 2]. Onset of both sensory and motor block were earlier in RD $(9.89 \pm 2.34$ seconds) group than group RP (11.87 \pm 4.11 seconds) [Table -3 ] and they were statistically significant $(\mathrm{p}<0.011)$.

The duration of sensory and motor block were significantly greater in the group receiving dexmedetomidine (RD) $(\mathrm{p}<0.05)$ than group RP [Table - 3, Figure - 1]. The mean time from block placement to first request for pain medication, i.e. the duration of analgesia was $(535.71 \pm 50.21) \mathrm{min}$ in the dexmedetomidine group (RD) and $(501.79 \pm 48.91) \mathrm{min}$ in the normal saline group (RP). This difference was $(\mathrm{P}=0.003)$ statistically significant (Table - 4, Figure - 2). Total requirement of rescue analgesia as diclofenac sodium in first 24 hours was $(83.32 \pm 10.23) \mathrm{mg}$ in group $\mathrm{RD}$ and in group RP it was $(102.43 \pm 11.77) \mathrm{mg}$, which is statistically significant $(p<0.01)$ as well as clinically (Table -4$)$. Figure -3 shows that 
VAS score was of much higher value in group RP than RD group.

Again group RD suffered from bradycardia, which was statistically higher $(p<0.05)$ than group R. Other side effects were quiet comparable ( $p>0.05$ ) among two groups [Table - 5].

\section{DISCUSSION}

Trauma to the hand presents with multiple soft tissue and osseous manifestations. It is challenging to assess and treat the crushed hand. These are multisystem combined injuries that can lead to suboptimal functional recovery based on the severity of the tissue trauma alone.[13-15] Aggressive initial management affords the best chance to optimize results. The cornerstone of care is the identification of the pathoanatomy, assessment of the magnitude of the injuries, and focused treatment in the context of the complete injury.[1]

This is a situation where early exploration of the wound is required. There is no time available to prepare the stomach keeping the individual in fasting. Rather early administration of anaesthesia is required. After primary examination of the patient excluding other injuries like head and neck, chest, abdominal injuries and confirming consciousness we usually administer regional anaesthesia in the form of brachial plexus block to explore the wound and proceed for necessary surgical corrections. It provides effective motor and sensory block as well as a good analgesia of certain duration. The duration depends on the drugs used. A drug that has a faster onset, longer duration of action and minimal toxicity profile could be an advantage.

Ropivacaine is a long-acting amide local anaesthetic with a potentially improved safety profile when contrasted to bupivacaine. $[16,17]$ The fact that ropivacaine may offer less cardiac and neurologic toxicity suggests a potential clinical advantage of this drug during neural blockade when large volumes of local anesthetic are required. In the initial studies in humans $0.5 \%$ ropivacaine, both with and without epinephrine provided effective sensory and motor blockade when used to provide brachial plexus anesthesia.[18] In this study we choose ropivacaine $0.5 \%$ as local anaesthetic for supraclavicular brachial plexus block.

Dexmedetomidine is highly selective (Eight time more selective than clonidine).[7] specific and potent $\alpha_{2}$-adrenergic agonist having analgesic, sedative, antihypertensive and anaesthetic sparing effects when used in systemic route.[8] Adding dexmedetomidine to local anaesthetics during peripheral nerve blockade.[9] and regional anaesthesia.[10] procedures may also prove efficacious for the surgical patients. In human study, dexmedetomidine has also shown to prolong the duration of block and post-operative analgesia when added to local anaesthetic in various regional blocks.[11,12] We added $100 \mu \mathrm{g}$ dexmedetomidine $(1 \mathrm{ml})$ to $0.5 \%$ ropivacaine $(30 \mathrm{ml})$ for group $\mathrm{RD}$ and added $1 \mathrm{ml}$ normal saline for group RP to prepare blocking solution.

Regarding age distribution, both in group RD and RP were younger group of population aged between 18 to 30 years. Another important demographic parameter is sex ratio. It was found that $84.21 \%$ of population in group RD were male and in group RP it was $61.45 \%$. These are important in context of economical loss of the society and family. But these differences were not statically significant between two groups. Other demographic profiles were quite comparable among two groups. Regarding type of injury [Table - 2], it is clear that larger number of patient required minor operative intervention, but significant number of individuals required complex orthopaedic and multidisciplinary intervention to save the limb and restore limb function. For complex neurovascular and bone injuries, early intervention is very important to reduce disabilities and to restore limb function.
In 2013, Gupta et Al. in their review with demographic profile of hand injuries in an industrial town of north India also found similar demographic tendency as we found in our study with industrial hand injury.[1]

In our study, the loss of pinprick sensation or the onset of sensory block ( 9.89 vs. $11.87 \mathrm{~min}$ ) in group RD was earlier than group RP. Ammar and Mahmoud.[10] Kaygusuz et al.[19] in their studies, also found similar early onset of sensory block when dexmedetomidine used as an adjuvant to ropivacaine for brachial plexus block. The loss of flexion of forearm or onset time of motor block (18.51 vs. $20.12 \mathrm{~min}$ ) in RD group was also earlier in group RP ( $p=0.03)$. Ammar and Mahmoud.[10] Gandhi et al.[20] in their study found that motor block onset was hastened with the use of dexmedetomidine to local anaesthtic.

In our study, the duration of sensory block (515.32 vs. $485.43 \mathrm{~min}$ ) in group RD was significantly longer in the dexmedetomidine group than in the control group $(\mathrm{p}<0.01)$. The duration of motor block (378.32 vs. $350.94 \mathrm{~min}$ ) was also significantly longer in the dexmedetomidine group than in the control group ( $p$ value $=0.033$ ). Earlier studies by Ammar and Mahmoud.[10] Esmaoglu et al.[11] Rancourt et al.[21] Marhofer et al.[22] also found similar trend of prolongation in motor and sensory block with dexmedetomidine.

Time to request for first rescue analgesic or VAS score $>3$ was significantly prolonged (535.71 vs. $501.79 \mathrm{~min}$ ) with dexmedetomidine group $(\mathrm{p}<0.01)$ when compared with placebo. Total amount of injection diclofenac sodium required during first 24 hours of postoperative period was much lower in group RD (83.32 vs. $102.43 \mathrm{mg}$ ) than $\mathrm{RP}$ ( $\mathrm{p}$ value<0.01). Ammar and Mahmoud.[10] also experienced statistically much less amount ( 4.9 vs. $13.6 \mathrm{mg}$ ) of IV morphine consumption as rescue analgesic in patients received dexmedetomidine. Another important observation was the VAS score in the postoperative period (Figure - 3). It was found that VAS score was much lower in patients who received dexmedetomidine. Thus it is clearly evident that addition of dexmedetomidine enhanced both motor and sensory block and provided better postoperative analgesia than ropivacaine alone.

Two patients in the dexmedetomidine group and three patients in the placebo group presented with cough after injection and managed well with oxygen supplementation. They were later diagnosed as pneumothorax radiologically and fortunately none of them required any operative intervention for that chink of pneumothorax evident radiologically. This side effect was not statistically significant between two groups ( $p>0.05)$. This was probably a procedural complication. The incidence of Horner syndrome was found in six patients in group RD and three patients of group RP. But the difference was not statistically significant $(\mathrm{p}=0.07)$.

Bradycardia was observed in four patients of group RD compared to one in group RP, which was significant statistically $(p<0.01)$. All of these patients were managed with atropine without any complications. Six patients in group RD and three in group RP were observed to have systolic blood pressure less than $100 \mathrm{mmHg}$ and were marked as incidence of hypotension. The difference was not significant $(p>0.05)$. Episodes of hypotension were managed well with increased rate of infusion of crystalloids and atropine. No other vasopressor were required. Several hypothesized mechanisms of action have been suggested to explain the analgesic effect of dexmedetomidine. Some of these include vasoconstriction around the injection site.[23] direct suppression of impulse propagation through neurons as a result of a complex interaction with axonal ion channels or receptors,[24] local release of enkephalin-like substances.[25] a decrease in localized proinflammatory mediators. ${ }^{[26]}$ and an increase in anti-inflammatory cytokines through an $\alpha_{2}$-adrenoceptormediated mechanism. ${ }^{[27]}$ 
Finally unsuccessful block was encountered in two patients (5\%) in each group in our study, which is quite comparable to previous studies using nerve stimulator guided approaches to supraclavicular brachial plexus blockade.[28]

We do conclude that addition of $100 \mu \mathrm{g}$ dexmedetomidine to ropivacaine $0.5 \%$ solution in supraclavicular brachial plexus block prolongs the duration of sensory and motor blockade reduces the requirement of rescue analgesic in postoperative period and has an appreciable effect on the onset time of sensory and motor blockade. This can help to perform from a minor surgical procedure to complex one for bone, soft tissue and neurovascular injury of hand in industrial workers required longer duration under regional anaesthesia, where risks for general anesthesia specially because of full stomach can be bypassed. However, we suggest further dose response studies to optimize the dose of dexmedetomidine.

\section{REFERENCES}

1. Gupta A, Gupta AK, Uppal SK, Mittal RK, Garg R, Aggarwal N. Demographic Profile of Hand Injuries in an Industrial Town of North India: A Review of 436 Patients. Indian J Surg 2013;75:454-461.

2. Bazin JE, Massoni C, Groslier D, Fenies V, Bittar M, Schoeffler P. Brachial plexus block: effect of the addition of sufentanil to local anesthetic mixture on postoperative analgesia duration. Ann Fr Anesth Reanim 1997;16:9-13.

3. Kohli S, Kaur M, Sahoo S, Vajifdar H, Kohli P. Brachial plexus block: Comparison of two different doses of clonidine added to bupivacaine. J Anaesthesiol Clin Pharmacol 2013;29:491-5.

4. Yadav RK, Sah BP, Kumar P, Singh SN. Effectiveness of addition of neostigmine or dexamethasone to local anaesthetic in providing perioperative analgesia for brachial plexus block: A prospective, randomized, double blinded, controlled study. Kathmandu Univ Med J 2008;6:302-9.

5. Jarbo K, Batra YK, Panda NB. Brachial plexus block with midazolam and bupivacaine improves analgesia. Can J Anaesth 2005;52:822-6.

6. Dogru K, Yildirim D, Ulgey A, Aksu R, Bicer C, Boyaci A. Adding magnesium to levobupivacaine for axillary brachial plexus block in arteriovenous fistule surgery. Bratisl Lek Listy 2012;113:607-9.

7. Gerlach AT, Dasta JF. Dexmedetomidine: an updated review. Ann Pharmacother 2007;41:245-52.

8. Huang R, Hertz L. Receptor subtype and dose dependence of dexmedetomidine-induced accumulation of [14C] glutamate in astrocytes suggests glial involvement in its hypnotic-sedative and anesthetic-sparing effects. Brain Res 2000;873:297-301.

9. Kettner SC. Dexmedetomidine as adjuvant for peripheral nerve blocks. Br J Anaesth 2013;111:123.

10. Ammar AS, Mahmoud KM. Ultrasound-guided single injection infraclavicular brachial plexus block using bupivacaine alone or combined with dexmedetomidine for pain control in upper limb surgery: A prospective randomized controlled trial. Saudi J Anaesth 2012;6:109-14.
11. Esmaoglu A, Yegenoglu F, Akin A, Turk CY. Dexmedetomidine added to levobupivacaine prolongs axillary brachial plexus block. Anaesth Analg 2010;111:1548-51.

12. Obayah GM, Refaie A, Aboushanab 0 , Ibraheem $\mathrm{N}$, Abdelazees M. Addition of dexmedetomidine to Bupivacaine for greater palatine nerve block prolongs postoperative analgesia after cleft palate repair. Eur J Anaesthesiol 2010;27:280-4.

13. Sandzen SC, Jr. Crush injuries of the hand and fingers. I. Med Trial Tech Q 1972;19:144-151.

14. Sandzen SC, Jr. Crush injuries of the hand and fingers. III. Med Trial Tech Q 1973;19:418-431.

15. Sandzen SC, Jr. Crush injuries of the hand and fingers. II. Med Trial Tech Q 1973;19:282-289.

16. Scott DB, Lee A, Fagan D, Bowler GM, Bloomfield P, Lundh R. Acute toxicity of ropivacaine compared with that of bupivacaine. Anesth Analg 1989;69:563-9.

17. Arthur GR, Feldman HS, Covino BG. Comparative pharmacokinetics of bupivacaine and ropivacaine, a new amide local anesthetic. Anesth Analg 1988;67:1053-8.

18. Hickeys R, Candido KD, Ramamurthy S. Brachial plexus block with a new local anesthetic $0.5 \%$ ropivacaine. Can J Anaesth 1990;37:732-8.

19. Kaygusuz K, Ozdemir I, Duger C, Gursoy S, Ozturk H, Kayacan U, et al. Effects of adding dexmedetomidine to levobupivacaine in axillary brachial plexus block. Current therapeutic research 2012;73:103-11.

20. Gandhi R, Shah A, Patel I. Use of dexmedetomidine along with bupivacaine for brachial plexus block. National journal of medical research 2012;2:67-69.

21. Rancourt MP, Albert NT, Cote M, Letourneau DR, Bernard PM. Posterior tibial nerve sensory blockade duration prolonged by adding dexmedetomidine to ropivacaine. Anesth Analg 2012;115:958-62.

22. Marhofer D, Kettner SC, Marhofer P, Pils S, Weber M, Zeitlinger $M$. Dexmedetomidine as an adjuvant to ropivacaine prolongs peripheral nerve block: a volunteer study. Br J Anaesth 2013;110:438-42.

23. Yoshitomi T, Kohjitani A, Maeda S, Higuchi H, Shimade M, Myawaki T. Dexmedetomidine enhances the local anesthetic action of lidocaine via an alpha-2A adrenoceptor. Anesth Analg 2008;107:96-101.

24. Kosugi T, Mizuta K, Fujita T, Nakashima M, Kumamoto E. High concentrations of dexmedetomidine inhibit compound action potentials in frog sciatic nerves without alpha (2) adrenoceptor activation. $\mathrm{Br} \mathrm{J}$ Pharmacol 2010;160:1662-76.

25. Fürst $S$. Transmitters involved in antinociception in the spinal cord. Brain Res Bull 1999;48:129-41.

26. Kawasaki T, Kawasaki C, Ueki M, Hamada K, Habe K, Sata T. Dexmedetomidine suppresses proinflammatory mediator production in human whole blood in vitro. J Trauma Acute Care Surg 2013;74:1370-5.

27. Xu L, Bao H, Si Y, Wang X. Effects of dexmedetomidine on early and late cytokines during polymicrobial sepsis in mice. Inflamm Res 2013;62:507-14.

28. Franco CD, Vieira ZE. 1001 subclavian perivascular brachial plexus blocks: success with a nerve stimulator. Reg Anesth Pain Med 2000;25:41-6. 


\begin{tabular}{|c|c|c|c|}
\hline Parameter & $\begin{array}{c}\text { Group RD (n=38) } \\
\text { Ropivacaine+ Dexmedetomidine }\end{array}$ & $\begin{array}{c}\text { Group RP (n=38) } \\
\text { Ropivacaine + Placebo }\end{array}$ & P value \\
\hline Age (years) & $24.57 \pm 5.23$ & $22.88 \pm 4.72$ & 0.1434 \\
\hline Bodyweight (Kg) & $63.11 \pm 7.81$ & $61.45 \pm 8.73$ & 0.3852 \\
\hline Sex (Female/Male) & $6(15.78 \%): 32(84.21 \%)$ & $8(21.05 \%): 30(78.94 \%)$ & 0.4261 \\
\hline Height (cm) & $159.49 \pm 12.65$ & $157.11 \pm 15.75$ & 0.4700 \\
\hline ASA physical status (I/II) & $35(92.10 \%) / 3(7.89 \%)$ & $33(86.84 \%) / 5(13.15 \%)$ & 0.3371 \\
\hline Surgery time (min) & $60.13 \pm 6.10$ & $62.41 \pm 7.32$ & 0.1444 \\
\hline Tourniquet time (min) & $64.34 \pm 7.09$ & $67.11 \pm 8.18$ & 0.1190 \\
\hline Anaesthesia time (min) & $95.23 \pm 10.23$ & $92.66 \pm 11.32$ & 0.3025 \\
\hline \multicolumn{2}{r|}{ Table 1: Comparison of Demographic Data Between the Two Study Groups } \\
\hline
\end{tabular}

\begin{tabular}{|c|c|c|}
\hline Indications for Upper Limb Surgery & Group RD (n=38) & Group RP (n=38) \\
\hline Open wound of fingers \pm damage to nail & $4(10.53 \%)$ & $6(15.78 \%)$ \\
\hline \# of multiple phalanx & $4(10.53 \%)$ & $5(13.15 \%)$ \\
\hline \# of metacarpal bones/phalanx & $9(23.68 \%)$ & $7(18.42 \%)$ \\
\hline Injury of ulnar nerve at wrist \& hand level & $7(18.42 \%)$ & $6(15.78 \%)$ \\
\hline Injury of mixed nerve at wrist \& hand level & $2(5.26 \%)$ & $4(10.53 \%)$ \\
\hline Injury of extensor muscles and tendon & $6(15.78 \%)$ & $5(13.15 \%)$ \\
\hline Traumatic amputation of single finger & $3(7.89 \%)$ & $4(10.53 \%)$ \\
\hline Traumatic amputation of thumb & $3(7.89 \%)$ & $1(2.63 \%)$ \\
\hline \multicolumn{3}{|c|}{ Table 2: Indications of Upper Limb Orthopaedic Surgery for Two Groups } \\
\hline
\end{tabular}

(Data are $\mathrm{n}=\%$ )

\begin{tabular}{|c|c|c|c|}
\hline Parameters & Group RD (n=38) & Group RP (n=38) & Pvalue \\
\hline Time taken to achieve Sensory Blockade (min) & $9.89 \pm 2.34$ & $11.87 \pm 4.11$ & 0.0118 \\
\hline Time taken to achieve Motor Blockade (min) & $18.51 \pm 2.71$ & $20.12 \pm 3.59$ & 0.0305 \\
\hline Duration of Sensory Blockade (min) & $515.32 \pm 47.40$ & $485.43 \pm 43.11$ & 0.0053 \\
\hline Duration of Motor Blockade (min) & $378.32 \pm 57.02$ & $350.94 \pm 53.29$ & 0.0338 \\
\hline
\end{tabular}

\begin{tabular}{|c|c|c|c|}
\hline & Group RD (n=38) & Group RP (n=38) & P value \\
\hline Request of 1st Analgesic (min) & $535.71 \pm 50.21$ & $501.79 \pm 48.91$ & 0.0039 \\
\hline Rescue analgesia as Diclofenac Sodium (mg) & $83.32 \pm 10.23$ & $102.43 \pm 11.77$ & 0.0001 \\
\hline \multicolumn{3}{|c|}{ Table 4: Rescue Analgesic Requirement in Post-Operative Period } \\
(Time and Amount of IM Diclofenac Sodium Injections) \\
\hline
\end{tabular}

\begin{tabular}{|c|c|c|c|}
\hline Side Effects & Group RD (n=38) & Group RP (n=38) & P value \\
\hline Pneumothorax & 2 & 3 & 0.4362 \\
\hline Horner syndrome & 6 & 3 & 0.0711 \\
\hline Bradycardia $(\mathrm{HR}<60 \mathrm{bpm})$ & 4 & 1 & 0.0023 \\
\hline Hypotension(SBP<100 mmHg) & 6 & 3 & 0.0711 \\
\hline \multicolumn{3}{|c|}{ Table 5: Comparison of Side Effects } \\
\hline
\end{tabular}

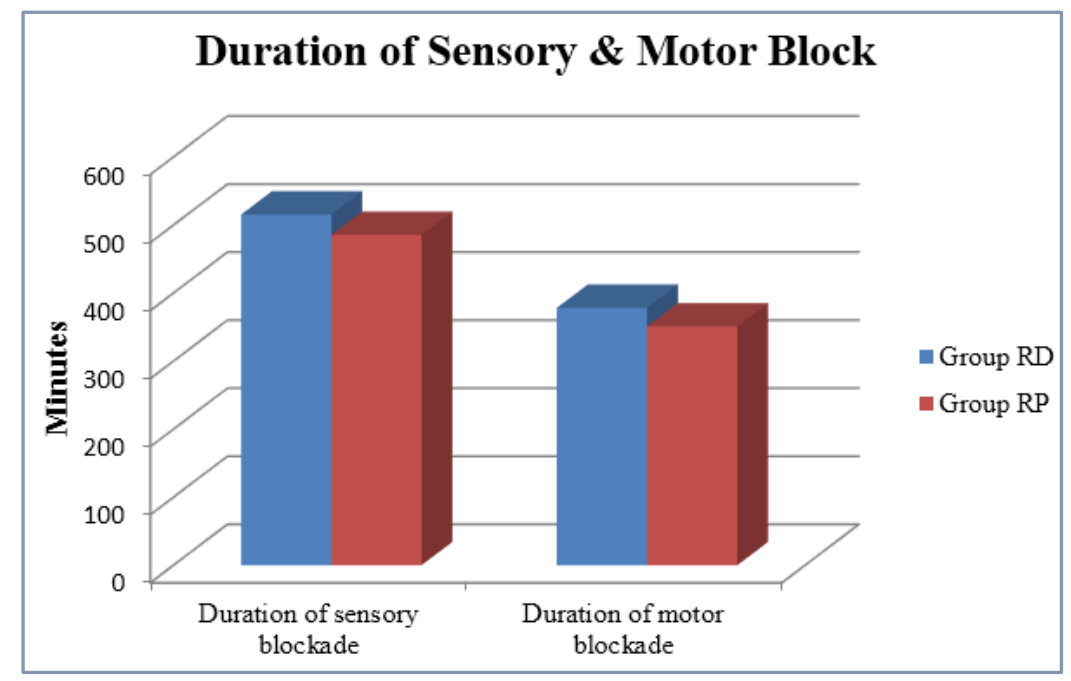

Fig. 1: Duration of Sensory and Motor Block 


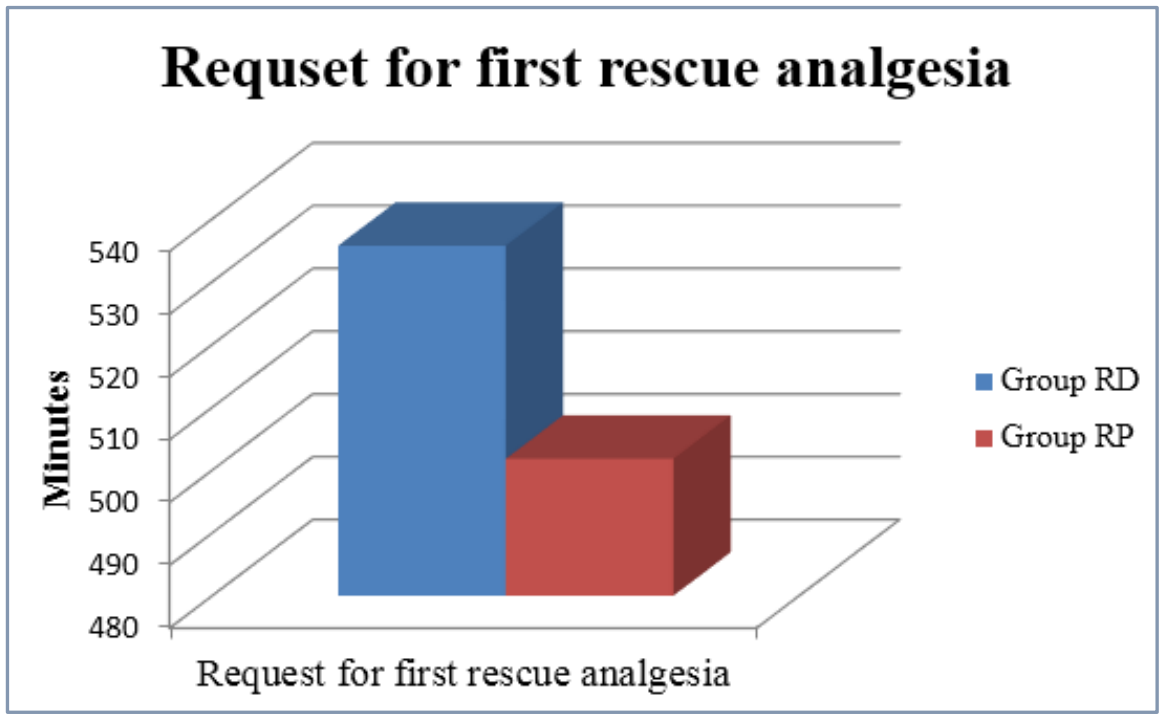

Fig. 2: Time to Administer First Rescue Analgesic

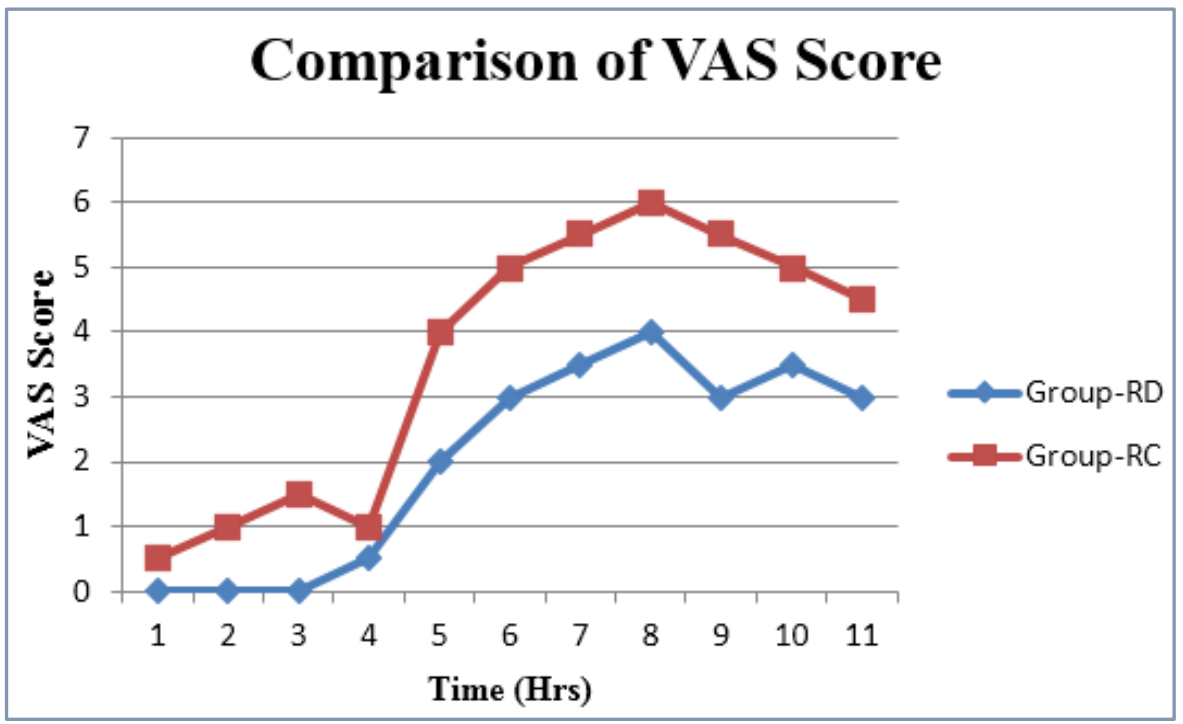

Fig. 3: Comparison of Visual Analog Scale (VAS) Score Among Groups RD and Group RP 